International Journal of Engineering \& Technology, $7(4.20)(2018) 372-376$
International Journal of Engineering \& Technology
SPC
Website: www.sciencepubco.com/index.php/IJET
Research paper

\title{
Improvement of Gypsum Soil by Using Polyurethane to Reduce Erosion and Solubility of Irrigation Canals
}

\author{
Maysam Th. Al-Hadidi ${ }^{1}$, Atheer G. Ibrahim ${ }^{2}$ \\ 1,2 University of Baghdad, College of Engineering, Water Resources Eng. Dept. \\ * Corresponding author E-mail :mays.thamer@coeng.uobaghdad.edu.iq
}

\begin{abstract}
The reducing of erosion and the solubility of irrigation canals soils which constructed on gypsum soil is important in civil and water resources engineering. The main problem of gypsum soils is the presence of gypsum which represents one of most complex engineering problems, especially when accompanied by the moving of water which represent dynamic load along the canal. There are several solutions to this problem, in this research "Poly urethane" is used to give the gypsum soil sufficient hardness to reduce the solubility and erosion, after compacting the soil in the canal, percentages of Poly urethane was used to making cover to the soil by mixing percent of soil with Poly urethane, and the ratio was as follows: (5 and 10) \% and the percent of Poly urethane were as follows: $6 \%, 10 \%$, and $12 \%$. The collapsibility of the soil was calculated by measuring the height of the soil after the passage of water along the canal. This collapsibility was used as an index to calculate the erosion and the solubility of gypsum within the soil. The results show that the best percentage of poly urethane is (10\%), which gave small value in corrosion about (3\%) at 28 days.
\end{abstract}

Keywords: Collapsibility, Erosion, Gypsum Soil, Irrigation Canals, Poly Urethane, Solubility.

\section{Introduction}

The gypsum soils is located is arid and semi-arid regions, and cover about $31.7 \%$ of Iraq (AL-Emami, 2007). The Chemical formula for The Gypsum is $\left(\mathrm{CaSO}_{4} \cdot 2 \mathrm{H}_{2} \mathrm{O}\right)$ (Al-Mufty, 1997), and there are two types of gypsum is soil:

A) First type consist of $\left(\mathrm{CaSO}_{4} \cdot 2 \mathrm{H}_{2} \mathrm{O}\right)$ as gypsum, $\left(\mathrm{CaSO}_{4}\right)$ as anhydrite, and (light clolored, a fine grained) as alabaster.

B) Second type is formed by one or more of these points:

1) Dissolution of primary rocks.

2) Evaporation of ground water. (Ibrahem, 2018)

The collapsible soil is defined as unsaturated soil specially when adding load on it, this leads to rearrangement it's particles and loss great of its volume upon wetting (Alahmar, 2010).

Gypsum soil has specific deficiency in the permeability and stability of canals and embankment for geotechnical engineering. The materials used in cover the surface of the soil are to reduce the soil permeability into the body of the soil (Liu et al., 2017).

Mixing of Poly urethane with the soil (PMS) is used to reinforce the soil. Reinforcement mechanism is discussed by measuring the height of the soil after the passage of water along the canal and this was done by taking points on the soil surface (Al-Maamori, 2018). The result indicated that the permeability of soil reinforce with Poly urethane decreases through the formation of reinforcement layer on the surface of the soil. The thickness of the reinforcement layer increase when there is increasing in the concentration of the Polymer. Increasing of the Polymer's concentration (PC) leads to decreases the permeability coefficient, and increases it with the increasing of the canal depth. PC fills out the voids of soil to prevent or reduce the flowing channels of water; this leads to decreases the permeability of the soil and therefore reduces the collapsibility of the soil and the erosion (Liu et al., 2017).

\subsection{Experimental outlines:}

\subsubsection{The flume}

The flume that has been used in the laboratory of water resources engineering department, university of Baghdad, consists of stainless steel channel bed and glass walls, has (9) m length, (30) $\mathrm{cm}$ width and (30) $\mathrm{cm}$ depth. This flume is divided into four main parts, the first part is the slope channel controlling. The second part is called inlet tank, in which water enters into it through a tube subjects between the pump and the tank. The third part is the reservoir at the end of the flume which contains the accumulative water that coming from the section of the working. The last part is the two screens to avoid unwanted particles for entering, the first one at the tank while the second at the end of the flume before the water arrives the reservoir. Fig. 1 shows the used flume and its parts.

\subsubsection{Materials.}

The soil that used in this study has been brought from Karbala government.

Polymer: when two chemical liquids, polyol and as isocyanate, interact together in the presence of additives, the Poly urethane solution will be composed (Husain, 1999). The type of Poly urethane was used in this study (Figure 2).

The polymer is light yellow of oil liquid; its $\mathrm{pH}$ is 6-7, viscosity $650-700 \mathrm{mPa}$.s, specific gravity of $1.18 \mathrm{~g} / \mathrm{cm}^{3}$ and coagulation time of 30-1800 s (Liu et al., 2017).

The polymer has the primary advantages (Liu et al., 2017): 
(A) It interactions with water to form the Foam (elastic and viscous reinforced layer on surface of the soil) with excellent mechanical feature.

(B) It is an environment friendly material with no pollution, and it is a type of biodegradable water-soluble polymer.

(C) It has a low cost and easy to produce it.

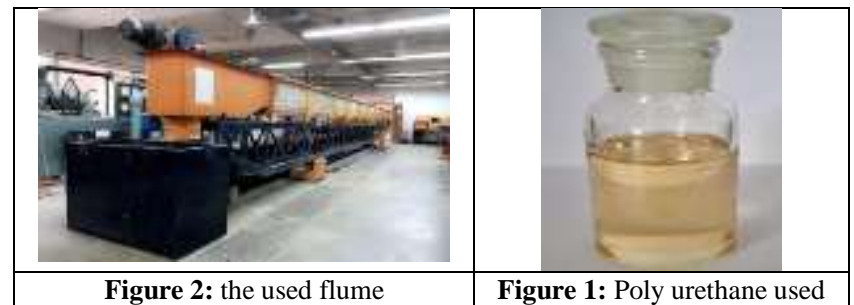

\subsubsection{Experimental Methods:}

PMS is a cover putting on the soil surface to form a reinforcement layer. In this study, the laboratory tests is calculate erosion and solubility of soil by measuring the height of the soil after the passage of water along the canal and this was done by taking points on the soil surface with time ( 7,14 and 28 day).

\subsubsection{Covering layer test form:}

The formation of the cover layer on soil surface is important to protect the surface slope. After bringing the soil, the following tests are made:

- The gypsum ratio :

The gypsum ratio is found in the method presented by (AlMaamori, 2018):

This method consists of drying the soil in an oven at $\left(45^{\circ} \mathrm{C}\right)$ until the weight of the sample is fix. The weight of the sample is record at $45^{\circ} \mathrm{C}$. The previous sample dry at $\left(110^{\circ} \mathrm{C}\right)$ for 1 day and the weight is record again. After that the gypsum content is calculate according to the following equation:

$X(\%)=\frac{w 45^{\circ} c-w 110^{\circ} c}{w 45^{\circ} c} * 4.778 * 100 \%$

Where:

$\mathrm{X}(\%)=$ Gypsum content $(\%)$.

$\mathrm{W} 45^{\circ} \mathrm{c}=$ Sample weight at $(45 \circ \mathrm{C})$

$\mathrm{W} 110^{\circ} \mathrm{C}=$ Sample weight at $(110 \circ \mathrm{C})$.

The percent of gypsum found is $41 \%$.

Standard sieve analysis: Standard sieve analysis test according to ASTM standard no.D421 test is made and the result shown in figure 3.

From the particle size distribution it's found that its particles have $\left(D_{60}\right)$ of $1.1 \mathrm{~mm}$, graduation coefficient $\left(C_{g}\right)$ of $0.69, \mathrm{~mm}$ and uniformity coefficient $\left(C_{u}\right)$ of $6.111 \mathrm{~mm}$.

The compaction test: The compaction test according to ASTM standard no.D698 and the results are: Maximum dry density is 1.7 $\mathrm{g} / \mathrm{cm}^{3}$. As shown in figure (4)

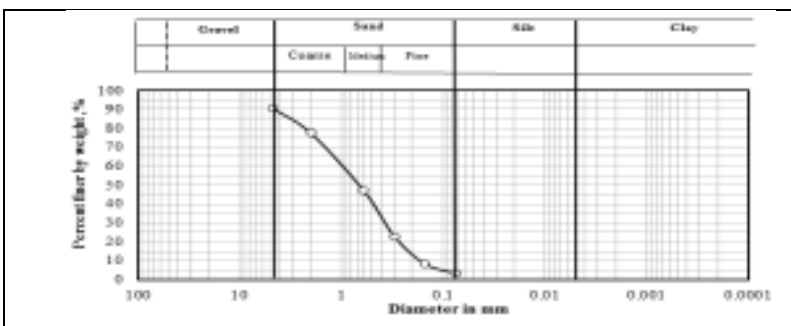

Fig. 3: grain size distribution.

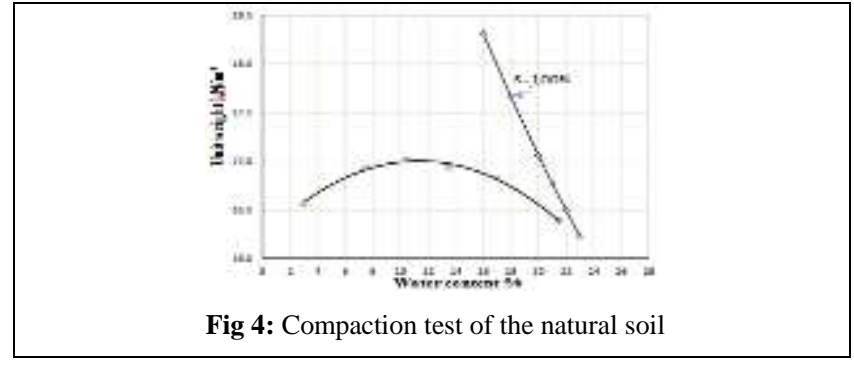

The mixing between the soil and Poly urethane was done to making the cover above the compaction soil in the canal model this cover is done in two ratio $5 \%$ and $10 \%$ with each percent three ratio of Poly urethane were mixed $(6 \%, 10 \%$, and $12 \%)$.

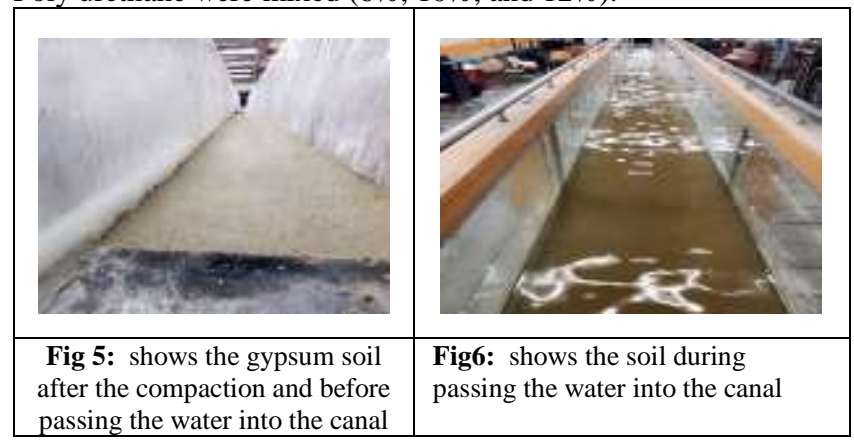

\subsubsection{Flow characteristics:}

The flow characteristics are shown in table 1.

Table 1: The flow characteristics

\begin{tabular}{|c|c|c|l|}
\hline Fr & \multicolumn{1}{|c|}{$\boldsymbol{Q}_{\boldsymbol{l} / \boldsymbol{s}}$} & $\boldsymbol{V}_{\boldsymbol{m}} / \boldsymbol{s}$ & Depth of water $(\mathrm{m})$ \\
\hline 0.239 & 11.967 & 0.2819 & 0.1415 \\
\hline
\end{tabular}

\subsubsection{Measuring the height of the soil:}

After the passage of the water along the canal (above the soil), we used the point gage and measured the height of the soil. The measurement process was performed on the basis of the readings of a contour map, as shown in figure 7:

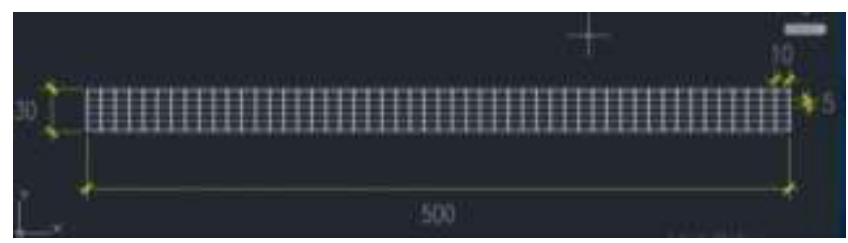

Fig. 7: The points on the surface soil (in the canal) whose readings were taken.

After taking the readings, (Surfer V 13) software was used to draw the contour maps to showing the change in elevations of soil points with time ( 28 days from above drawn to the bottom one, as shown in figures (8):

Figure 8a: show the contour map for surface levels of the natural soil, this figure shows that the soil suffers high change in elevation with time, with maximum level $(10 \mathrm{~cm})$ before starting take the readings. ; Also shows the minimum reading of the soil elevation is $(4.4 \mathrm{~cm})$ after taking the last reading at 28 days.

Figure 8b: Show the contour map for surface levels of (treatment soil ratio as $5 \%$ ) with (ratio of Poly urethane $6 \%$ ). This figure show that there was a high change in levels of soil after 28 especially in the last two thirds of the channel; with maximum level $(10 \mathrm{~cm})$ before starting take the readings. The minimum reading is $(3.0 \mathrm{~cm})$ after taking the last reading at 28 days.

Figure 8c: Show the contour map for surface levels of (treatment soil ratio as 5\%) with (ratio of Poly urethane 10\%).this figure shows that there is a small rate of change in settlement of the soil 
with time; also the average height of the soil with time remained constant, with maximum level $(10 \mathrm{~cm})$ before starting take the readings. The minimum reading is $(9.2 \mathrm{~cm})$ after taking the last reading at 28 days.

Figure 8d: Show the contour map for surface levels of (treatment soil ratio as 5\%) with ratio of Polyurethane $12 \%$ ). This figure shows that the change in the soil elevation increased in small rate with time for the treated soil; with maximum level $(10 \mathrm{~cm})$ before starting take the readings. The minimum reading is $(9 \mathrm{~cm})$ after taking the last reading at 28 days.

Figure 8e: Show the contour map for surface levels of (treatment soil as ratio 10\%) with (ratio of Poly urethane 6\%). This figure shows that there is large erosion in a small region in the last third of the channel flume at 28 days; with maximum level $(10 \mathrm{~cm})$ before starting take the readings. The minimum reading is $(6 \mathrm{~cm})$ after taking the last reading at 28 days.

Fig. 8f: Show the contour map for surface levels of (treatment soil as ratio $10 \%$ ) with (ratio of Poly urethane 10\%). This figure shows that there is a little change in the elevations of the soil with time, because the mixture of soil with poly urethane prevents the erosion and made strong reinforcement layer, with maximum level $(10 \mathrm{~cm})$ before starting take the readings. The minimum reading is $(8.8 \mathrm{~cm})$ after taking the last reading at 28 days.

Fig. 8g: Show the contour map for surface levels of (treatment soil ratio as 10\%) with (ratio of Poly urethane 12\%). This figure shows that the erosion of the soil accrues in a small rate with time, the cover is rigid because the high percentage of polyurethane which gives the hardness of the cover, and the average height remained constant with respectively to time, with maximum level $(10 \mathrm{~cm})$ before starting take the readings. The minimum reading is $(9 \mathrm{~cm})$ after taking the last reading at 28 days.

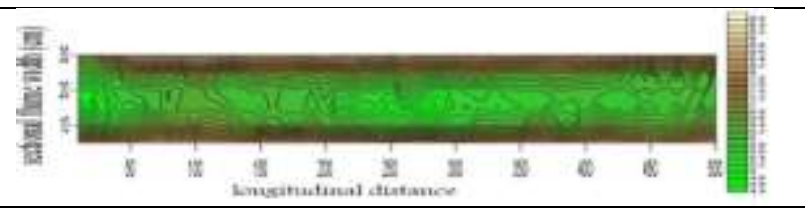

Fig. 8a: The contour maps for surface levels of the natural soil after 28days.

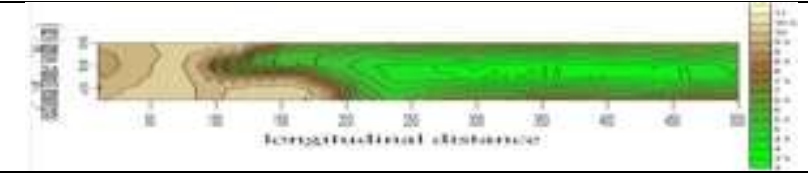

Fig. 8b: The contour maps for surface levels of (treatment soil ratio as $5 \%$ ) with (ratio of Poly urethane $6 \%$ ) after 28 days.

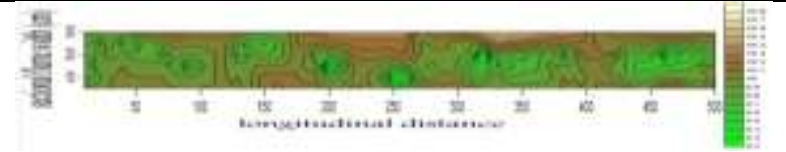

Fig. 8c: The contour maps for surface levels of (treatment soil ratio as $5 \%$ ) with (ratio of Poly urethane $10 \%$ ) after 28 days.

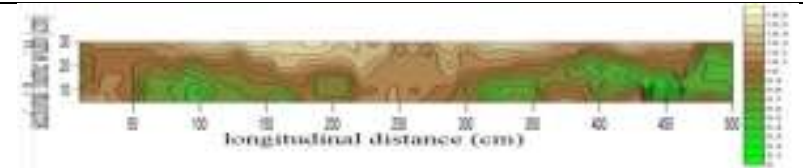

Fig. 8d: The contour maps for surface levels of (treatment soil ratio as $5 \%$ ) with ratio of Polyurethane $12 \%$ ) after 28 days

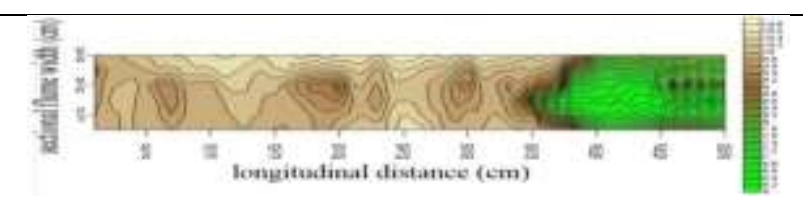

Fig. 8e: The contour maps for surface levels of (treatment soil as ratio $10 \%$ ) with (ratio of Poly urethane $6 \%$ ) after 28 days.

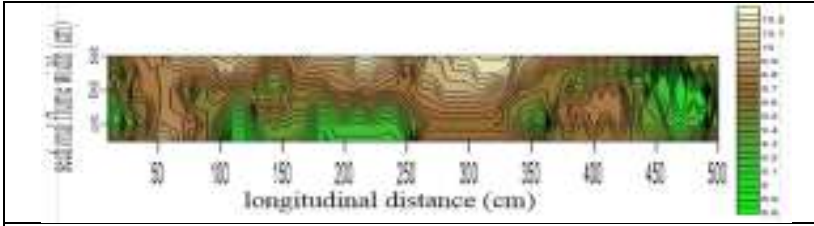

Fig. 8f: The contour maps for surface levels of (treatment soil as ratio $10 \%$ ) with (ratio of Poly urethane 10\%) after 28 days.

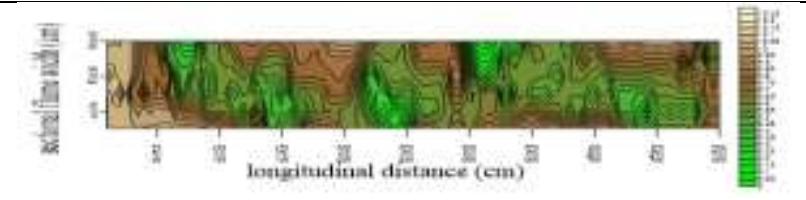

Fig. 8g: The contour maps for surface levels of (treatment soil ratio as $10 \%$ ) with (ratio of Poly urethane 12\%) after 28 days.

\section{Rates of improvement:}

Table (2) and table (3) shows the rates of improvement in the corrosion for the soil before and after using the polyurethane as a reinforcement layer, after 14 and 28 days respectively.

As we see, the corrosion is maximum when the percentage of Poly urethane is zero (There is no cover, compacted gypsum soil only), it decreases when the percentage of Poly urethane increase (creating the covers above the soil), and reached the maximum value when the percentage of poly urethane is (12\%).

From these tables, we find that the best percentage is $(10 \%)$, which gave small value of corrosion $(85.63 \%)$ for $(0.5 \mathrm{~cm}=5 \%$ soil $)$ and $(86.24 \%)$ for $(1 \mathrm{~cm}=10 \%$ soil $)$ at 14 days, While for 28 days, the value of corrosion is $(90.93 \%)$ for $(0.5 \mathrm{~cm}=5 \%$ soil $)$ and $(89.52 \%)$ for $(1 \mathrm{~cm}=10 \%$ soil $)$

Table 2 : The result of treatment after 14 day

\begin{tabular}{|c|c|c|c|c|}
\hline \multirow{2}{*}{$=$} & \multicolumn{2}{|c|}{ corrosion \% } & \multicolumn{2}{c|}{ redaction in corrosion \% } \\
\cline { 2 - 5 } & $\begin{array}{c}\mathbf{0 . 5} \mathbf{~ c m = 5 \%} \\
\text { soil }\end{array}$ & $\begin{array}{c}\mathbf{1} \mathbf{~ c m}= \\
\mathbf{1 0 \%} \text { soil }\end{array}$ & $\begin{array}{c}\mathbf{0 . 5} \mathbf{~ c m}=\mathbf{5 \%} \\
\text { soil }\end{array}$ & $\begin{array}{c}\mathbf{1} \mathbf{~ c m}= \\
\mathbf{1 0 \%} \text { soil }\end{array}$ \\
\hline 0 & 17 & 17 & & \\
\hline 6 & 13.88 & 10.68 & 18.35 & 37.18 \\
\hline 10 & 2.44 & 2.34 & 85.63 & 86.24 \\
\hline 12 & 2.29 & 2.18 & 86.55 & 87.19 \\
\hline
\end{tabular}

Table 3: The result of treatment after 28 day

\begin{tabular}{|c|c|c|c|c|}
\hline \multirow{2}{*}{\begin{tabular}{c|c|c|} 
corrosion \\
\cline { 2 - 5 }
\end{tabular}} & $\begin{array}{c}\mathbf{0 . 5} \mathbf{~ c m}=\mathbf{5 \%} \\
\text { soil }\end{array}$ & $\begin{array}{c}\mathbf{1} \mathbf{~ c m}= \\
\mathbf{1 0 \%} \text { soil }\end{array}$ & $\begin{array}{c}\mathbf{0 . 5} \mathbf{~ c m ~ = ~ 5 \% ~} \\
\text { soil }\end{array}$ & $\begin{array}{c}\mathbf{1} \mathbf{~ c m}= \\
\mathbf{1 0 \%} \text { soil }\end{array}$ \\
\hline 0 & 30.49 & 30.49 & & \\
\hline 6 & 24.05 & 11.24 & 21.11 & 63.12 \\
\hline 10 & 2.77 & 3.19 & 90.93 & 89.52 \\
\hline 12 & 3.55 & 3.28 & 88.34 & 89.24 \\
\hline
\end{tabular}

Tables (2) and (3): explain the percentage of the corrosion of the gypsum soil and the percentage of the reduction in the corrosion before and after treated the soil. As we see, the corrosion is maximum when the percentage of Poly urethane is zero (There is no cover, compacted gypsum soil only), it decreases when the percentage of Poly urethane increase (creating the covers above the soil), and reached the maximum value when the percentage of poly urethane is $(12 \%)$. From these tables, we find that the best percentage is $(10 \%)$, which gave small value of corrosion $(85.63 \%)$ for $(0.5 \mathrm{~cm}=5 \%$ soil $)$ and $(86.24 \%)$ for $(1 \mathrm{~cm}=10 \%$ soil $)$ at 14 days, While for 28 days, the value of corrosion is $(90.93 \%)$ for $(0.5$ $\mathrm{cm}=5 \%$ soil $)$ and $(89.52 \%)$ for $(1 \mathrm{~cm}=10 \%$ soil $)$. 


\section{Toxicity of the Polymer:}

\subsection{From a logical point of view:}

Microscopic and visual analyzes of the polyurethane samples were carried out after 14, 21 and 29 days of implantation in the dorsum of a mice. After evaluation of tissue samples removed after 14 days of transplantation, there was a simple inflammatory development in lymphocytes and fibroids. It can be compared after 29 days with moderate foreign bides, suggesting no long aggression on tissues (Dias, Góes, Serakides, Ayres, \& Oréfice, 2010).

After pervious introduction, it was necessary to ascertain whether there was interaction of water with the chemical or not? This was done by FTIR analysis. As shown in Figure (10) and (11).

\subsection{Experimentally:}

In this paragraph, we use Glass basin, put in it a specimen of soil with Poly urethane as shown in figure ( $8 \mathrm{a}$ and $8 \mathrm{~b}$ ):

This specimen after placing a quantity of water above it was exposed to the heat of the sun for the month of July and recorded the reading of the thermometer of the amount of water for each day of this month at $2 \mathrm{pm}$ and $4 \mathrm{pm}$. We found that the highest temperature recorded by the thermometer at $8 / 7 / 2018$ at $4 \mathrm{pm}$, as shown in figure (9)):

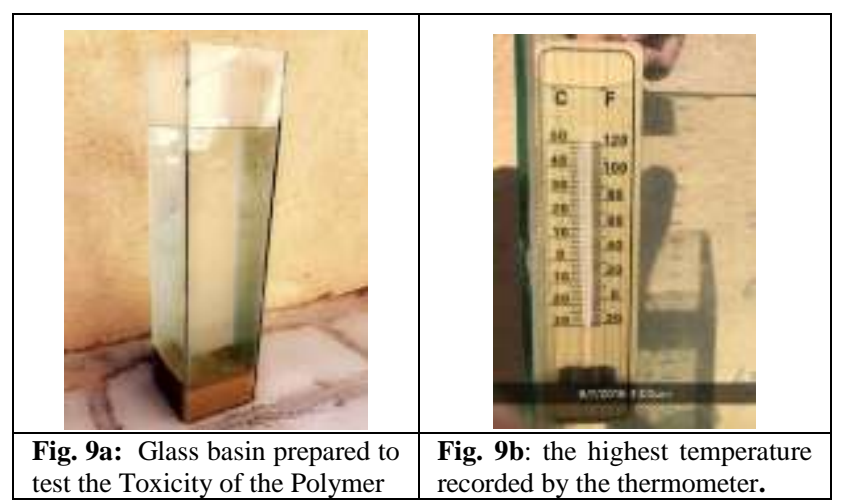

After preparing samples, the water is taken and checked it out in (FTIR) analysis.

FTIR analysis: Is a very powerful and general technique to investigate the structure of the material and to monitor the changes in the compounds of the organic and inorganic nanoparticles.

This technique measures the absorption of infrared radiation by the sample material versus wavelength. The infrared absorption bands identify molecular components, structures, chemical properties (Karim et al., 2015).

As shown in figure (10A and 10B).

We take five samples and analysis them .as shown in figure (10B): First one: water only, The second: water after put it above soil and Poly urethane and exposure it to the highest temperature of the sun, the Third one: water after put it above compaction soil, the Fourth: water after put the foam of the Polymer in it and the Fifth sample is solution of the Poly urethane only.

The results of the samples have shown as below:

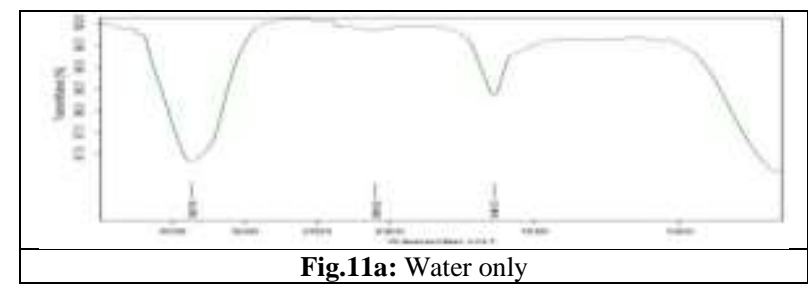

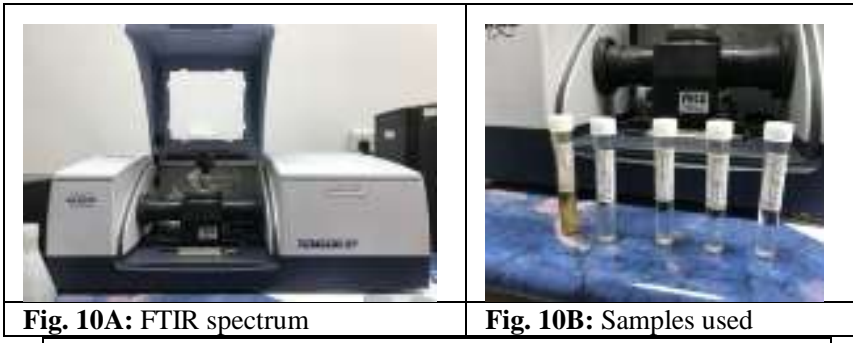

\begin{tabular}{l|l} 
Fig. 10A: FTIR spectrum & Fig. 10B: Samples used \\
\hline
\end{tabular}

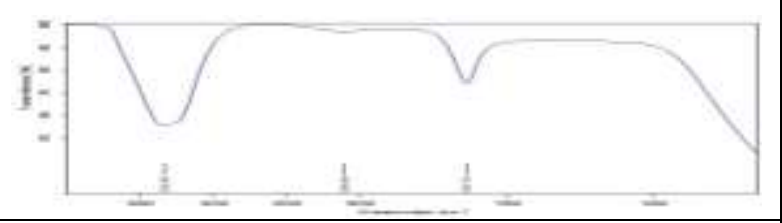

Fig.11b:Water after put it above soil and Poly urethane and exposure it to the highest temperature of the sun

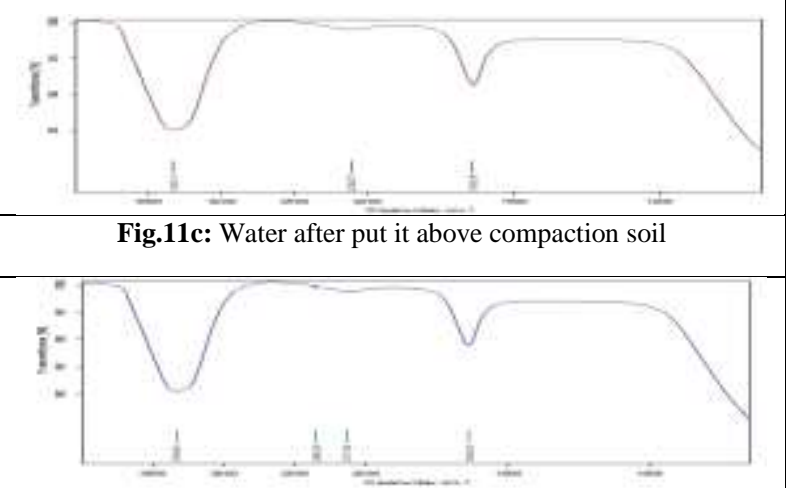

Fig.11d: Water after put the foam of the Polymer in it

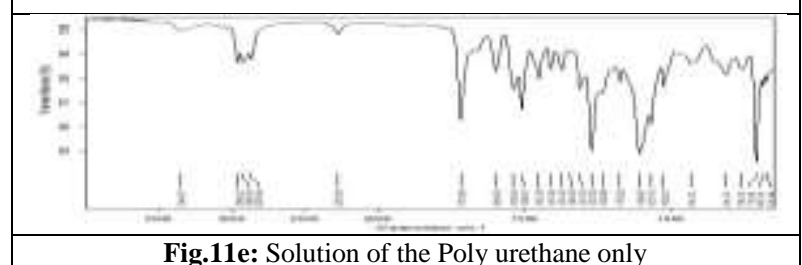

From the previous graphs, we notice that the $\mathrm{B}, \mathrm{C}$ and $\mathrm{D}$ graphs is similar to the A graph of water only, on the other hand A, B, C and $\mathrm{D}$ graphs contains only two peaks, while the $\mathrm{E}$ drawing contains multiple peaks showing the effect of the chemical, from this we conclude that there is no interaction of the polymer with the water after the hardening, i.e. there is no toxic effect on the water, and this is completely contrary to the fifth case (Fig. 11e), this case showing the Polymer alone as a solution without hardening with soil.

\section{Conclusions:}

According to the results of the present study, the following conclusions can be draw:

1. In the research with velocity equal to $(\mathbf{0 . 2 8 1 9} \mathrm{m} / \mathrm{s})$ and gypsum content of (41), the reduction in corrosion after 14 days was $(18.34$, 85.6 and 86.5$) \%$ for $(0.5 \mathrm{~cm}=\mathbf{5 \%})$ for percentages $(6 \%, 10 \%$ and $12 \%)$ of poly urethane respectively, while for $(1 \mathrm{~cm}=10 \%)$ the values was $(37.18,86.2$ and 87.19$) \%$ for percentages $(6 \%, 10 \%$, and $12 \%$ ) for polyurethane respectively. The reduction in corrosion after 28 days was $(21.11,90.9$ and 88.34$) \%$ for $(0.5 \mathrm{~cm}=5 \%)$ for percentages $(6 \%, 10 \%$ and $12 \%)$ of poly urethane respectively, while for $(1 \mathrm{~cm}=10 \%)$ the values were $(63.12,89.5$ and 89.23$) \%$ for 
percentages $(6 \%, 10 \%$, and $12 \%)$ for polyurethane respectively. from these results one can found the following:

A- If we compare the best percentage (10\%) with the other percentages $(6 \%, 12 \%)$ we will find that the percentage $(10 \%)$ gives results approach to the results of the percentage (12\%) for the corrosion and the reduction in the corrosion, so the percentage $(10 \%)$ was chosen because it is more economic, and at the same percentage of $(10 \%)$ for $(0.5 \mathrm{~cm}=\mathbf{5 \%}$ soil $)$ and $(1 \mathrm{~cm}=\mathbf{1 0 \%})$, there's no difference between them, but we need to study more to knowing which one is the best for the soil to give more rigidity and less erosion with solubility.

B- The best percentage of poly urethane is $(10 \%)$, which gave the sufficient hardness to the soil, and therefore reduce the erosion and the solubility of the soil.

2. From the previous graphs of the contour maps and rates of improvement, it shows that the rigidity of the cover increases with the increase of concentration of poly urethane. As a result, the erosion of the soil decreases with increase of concentration of poly urethane, and we notice that the rates of improvement decreases with time at a small rate, but this state is more better than the soil without any treating.

3. From the previous experimentally work, we found that there was no interaction of the water with the chemical, so we do not need to perform microscopic and visual analysis of "Poly urethane" samples after implantation in the sterilization of mice.

4. This research proposed method to treating gypsum soil by making cover about 5\% from the soil itself mixing with $10 \%$ with polyurethane.

\section{Recommendations:}

It must be study the change of rate of improvement of poly urethane with a long times to restrict the optimum age for covering by the polyurethane.

\section{Reference}

[1] AL-Emami, O. hassan F. (2007). Collapsibility of gypseous soil under fluctuation of ground water table. M.Sc. Thesis, University of Technology.

[2] Al-Maamori, Z. H. N. (2018). An Experimental Study Of Using Cement For Improving Earth Channels. M. Sc. Thesis, Water Resources Eng. Dep., University of Baghdad.

[3] Al-Mufty, A. A. (1997). Effect of gypsum dissolution on the mechanical behavior of gypseous soils. Unpublished Ph. D. Thesis, Civil Eng. Dep., University of Baghdad, Baghdad, Iraq.

[4] Alahmar, M. M. saeed ibrahim. (2010). Dynamic response of machine foundation on gypseous soil. University of Baghdad.

[5] Husain, H. K. (1999). an experimental study on the polyurethane modified concrete mixes. M. Sc. Thesis, Civil Eng. Dept.,University of Basrah.

[6] Ibrahem, O. M. (2018). relationship between void ratio and permeability for gypseous soil under dynamic load. M.Sc. Thesis, Civil Eng. Dept., University of Diyala.

[7] Karim, M. M., Karim, S. F. E., Rana, A. A., Masum, S. M., Mondol A., \& Israt, S. S. (2015). ATR-FTIR spectroscopy and chemometric techniques for the identification of edible vegetable oils. Bangladesh Journal of Scientific and Industrial Research, 50(4), 233-240.

[8] Liu, J., Qi, X., Zhang, D., Feng, Q., Wang, Y., \& Kanungo, D. P. (2017). Study on the permeability characteristics of polyurethane soil stabilizer reinforced sand. Advances in Materials Science and Engineering, 2017. 